\title{
Occult Breast Carcinoma with Axillary Lymph Node Metastasis in a Male Patient - An Evidence Based Approach
}

\author{
Vishwas D Pai ${ }^{{ }^{*}}$, Vidhya Manohar ${ }^{2}$, Kiran Kattimani $^{3}$, Padma Deshpande $^{4}$ and Satish Tumbal ${ }^{5}$ \\ ${ }^{1}$ Department of Surgical Oncology, Kerudi Cancer Hospital, Bagalkot, Karnataka, India \\ ${ }^{2}$ Department of Pathology, SRL Diagnostics, Banagalore, Karnataka, India \\ ${ }^{3}$ Department of Medical Oncology, Kerudi Cancer Hospital Centre, Bagalkot, Karnataka, India \\ ${ }^{4}$ Department of Nuclear Medicine, NMR Curie Centre, Hubli, Karnataka, India \\ ${ }^{5}$ Department of Radiodiagnosis, Kerudi Cancer Hospital, Bagalko, Karnataka, India
}

*Corresponding author: Vishwas D Pai, Department of Surgical Oncology, Kerudi Cancer Hospital, Bagalkot 587101, Karnataka, India, Tel:+91-9449333502; E-mail: vishpai88@gmail.com

Received date: June 04, 2016; Accepted date: July 27, 2015; Published date: August 04, 2015

Copyright: (c) 2016 Pai VD, et al. This is an open-access article distributed under the terms of the Creative Commons Attribution License, which permits unrestricted use, distribution, and reproduction in any medium, provided the original author and source are credited.

\begin{abstract}
Occult primary breast carcinoma (OPBC) with axillary lymph node metastasis is a rare disorder accounting for $0.1 \%$ to $0.8 \%$ of all the cases of breast cancer in females. Such a presentation in males is even rarer with only isolated case reports noted in English literature. Magnetic resonance imaging (MRI) of the breast detects primary tumor in nearly $2 / 3^{\text {rd }}$ patients. Role of mastectomy is considered controversial. There is no consensus on the role of adjuvant therapy owing to the rarity of these tumors. We are presenting an elderly man who presented with axillary lymph node metastasis of ductal carcinoma and was treated with surgery followed by adjuvant chemotherapy.
\end{abstract}

Keywords: Axillary lymph node metastasis; Unknown primary; Carcinoma with unknown primary

\section{Introduction}

Occult primary breast carcinoma (OPBC) is a condition characterized by the presence of regional or distant disease that is histologically consistent with a primary breast carcinoma in the absence of a demonstrable tumor in the breast based on clinical and radiological evaluation. This form of presentation is rare accounting for $0.1 \%$ to $0.8 \%$ of all the cases of breast cancer in females [1-3]. There is no consensus on the investigation as well as management of these cases owing to their rarity. We are presenting a case of occult primary breast carcinoma in an elderly male which was treated with surgery and adjuvant chemotherapy. Purpose of this presentation is to review the current evidence for the various management principles as well as to determine the role positron emission tomography (PET) scan in these cases.

\section{Case Report}

An 82-year-old gentleman presented with history of left axillary swelling of 6 months duration. On clinical examination he had an axillary nodal mass of size $6 \mathrm{~cm} \times 4 \mathrm{~cm}$, which was hard, matted and mobile. Ipsilateral and contra lateral breast and supraclavicular fossa didn't reveal any tumor or nodal mass. FNAC of the nodal mass revealed presence of metastatic carcinoma, although further characterization was not possible. Contrast enhanced computed tomography (CECT) of the thorax revealed axillary nodal mass with maintained fat planes with the axillary vein (Figure 1a). PET CT demonstrated uptake in the left axillary mass, but no other site of primary or metastatic disease (Figure $1 \mathrm{~b}$ ).

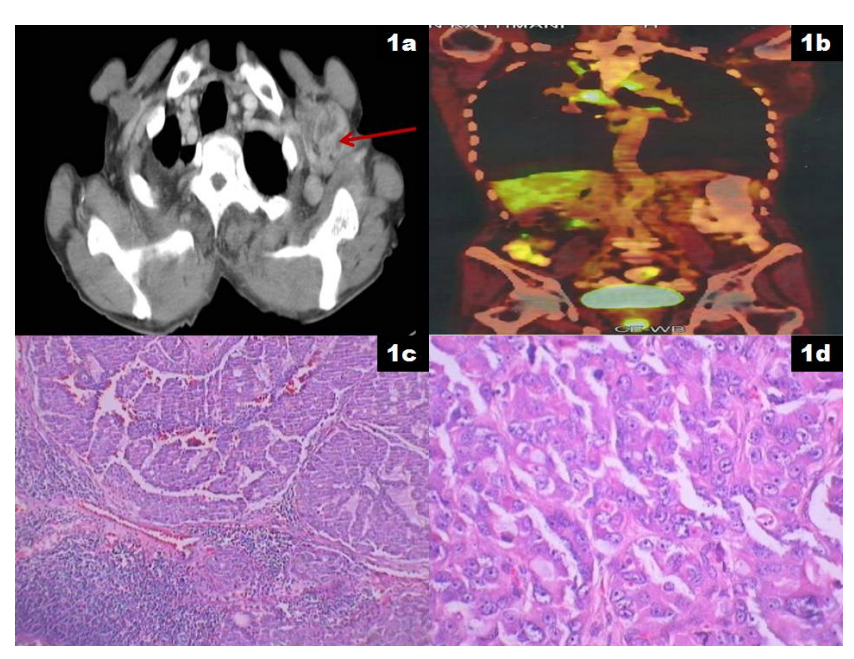

Figure 1: a) CECT thorax showing the left axillary nodal mass (red arrow) abutting the left axillary vein; b) PET CT showing no uptake in any other part of the body except left axilla; c) Photo micrograph showing lymph node partially replaced by a metastatic tumor arranged in tubules and clusters (H\&E, 40X); d) Photomicrograph showing a malignant tumor arranged in tubules, cords and cohesive clusters of pleomorphic, polygonal cells having vesicular nuclei with prominent nucleoli (H\&E, 400X).

Left axillary lymph node dissection involving level 1-3 nodes were removed. Intra and post-operative course were uneventful. Histopathological examination demonstrated metastatic carcinoma with tumour cells arranged in cribriform, complex glandular and 
pseudopapillary pattern with pools of extracellular mucin suggestive of metastatic adenocarcinoma (Figure $1 \mathrm{c}$ and $1 \mathrm{~d}$ ). Immunohistochemical (IHC) examination demonstrated positivity for estrogen receptor (ER), focal positivity for carcino embryonic antigen (CEA) and negativity for all the markers which confirmed it as occult breast carcinoma with axillary nodal metastasis. Post operatively he was treated with antracycline and taxane based chemotherapy for a total of 8 cycles. At last follow up, patient was disease free and in good health.

\section{Discussion}

Occult primary breast carcinoma with axillary nodal metastasis is a rare entity first described by Halsted in 1997 [4]. In general, $0.1 \%$ to $0.8 \%$ of all breast cancers is occult [1-3]. Male breast cancer accounts for $0.7 \%$ of all breast cancer worldwide [5]. OPBC in males is extremely rare with only few case reports available in English literature [6-9].

Optimum work up of the patients with OPBC is yet to be established. Although primary imaging modality for evaluating breast lesions is mammography (MMG), false negative rates of upto $30 \%$ have been reported for MMG [10,11]. The sensitivity of MMG further decreases in patients with dense breast parenchyma. Magnetic resonance imaging (MRI) of the breast appears to be promising in such cases. An MSKCC study found that MRI of the breast could identify primary tumor in 70\% patients of OPBC [12]. In addition, it was found that negative breast MRI predicted low tumor yield at mastectomy and hence could improve breast conservation rates in these patients. On similar lines, a recent systematic review found that MRI of the breast results in additional detection of otherwise occult lesions in cases of $\mathrm{OPBC}$ and can result in breast conservation in one thirds of patients of OPBC [13]. PET scan has revolutionized the management of carcinoma with unknown primary (CUP) at other subsites. However, it has not been evaluated in cases of OPBC. Present patient had PET scan done preoperatively which didn't reveal any site of primary disease.

Reported detection of tumor in mastectomy specimens in cases of OPBC ranges between $0 \%$ and $82 \%$ in various series [14-17]. In view of such wide variations, need for mastectomy in these cases has not been established. Vlastos et al. [1] found that there was no significant difference between those who underwent mastectomy and those who had breast preservation in terms of loco regional recurrence or 5 year overall survival. Most important prognostic factor in this series was the number of positive nodes. On the contrary, Wang et al. [18] found that disease free survival and overall survival was significantly better among those patients who underwent mastectomy. However, a recent metaanalysis comprising of 241 patients of OPBC found that mastectomy didn't lead to improved oncological outcomes compared to axillary lymph node dissection alone [19].

Role of breast radiotherapy for OPBC is considered controversial. A retrospective study from UK found that loco regional recurrence was significantly lower (28\% vs $53.7 \%)$ and 5 year breast cancer specific survival was significantly better ( $72 \%$ vs $58 \%)$ among those who received breast radiotherapy compared to those who didn't receive breast radiotherapy [20]. A recent meta-analysis found that breast radiotherapy was superior to axillary lymph node dissection alone with respect to loco regional recurrence $(12.7 \%$ vs $34.3 \%, \mathrm{p}<0.01)$ with a trend toward improved mortality rates $(9.5 \%$ vs $31.4 \%, \mathrm{p}=0.09)$ [21]. Barton et al. [15] found that $50 \mathrm{~Gy}$ in 25 fractions is the optimum radiotherapy dose in cases of OPBC and higher doses didn't lead to better oncological outcomes.
Systemic therapy has been the backbone of adjuvant therapy node positive breast cancer. None of the previous series of OPBC have specifically looked at the role of systemic therapy. These facts have to be considered in the background of the fact that endocrine therapy is associated with fewer side effects compared to chemotherapy. Hence it is reasonable to personalize adjuvant systemic therapy based on hormone receptor status, performance status of the patient and the nodal burden.

Most case series have reported improved outcomes for patients presenting with $\mathrm{OPBC}$ compared to those presenting with non-occult breast cancers with similar nodal involvement. However, a few have reported outcomes that are comparable or even worse. However, in all the series, lymph node burden is found to be the most important prognostic factor.

\section{Conclusion}

The purpose of the presenting this case was highlights the rarity of $\mathrm{OPBC}$ and critically reviews the literature for the current evidence for treating such cases. Role of PET scan needs to be evaluated in these cases.

\section{References}

1. Vlastos G, Jean ME, Mirza AN, Mirza NQ, Kuerer HM, et al. (2001) Feasibility of breast preservation in the treatment of occult primary carcinoma presenting with axillary metastases. Ann Surg Oncol 8: 425-431.

2. Montagna E, Bagnardi V, Rotmensz N, Viale G, Cancello G, et al. (2011) Immunohistochemically defined subtypes and outcome in occult breast carcinoma with axillary presentation. Breast Cancer Res Treat 129: 867-875.

3. Patel J, Nemoto T, Rosner D, Dao TL, Pickren JW (1981) Axillary lymph node metastasis from an occult breast cancer. Cancer 47: 2923-2927.

4. Halsted WS (1907) The Results of Radical Operations for the Cure of Carcinoma of the Breast. Ann Surg 46: 1-19.

5. Siegel R, Naishadham D, Jemal A (2013) Cancer statistics, 2013. CA Cancer J Clin 63: 11-30.

6. Rosen PP, Kimmel M (1990) Occult breast carcinoma presenting with axillary lymph node metastases: a follow-up study of 48 patients. Hum Pathol 21: 518-523.

7. Gu GL, Wang SL, Wei XM, Ren L, Zou FX (2009) Axillary Metastasis as the First Manifestation of Occult Breast Cancer in a Male Patient. Breast Care (Basel) 4: 43-45.

8. Hur SM, Cho DH, Lee SK, Choi MY, Bae SY, et al. (2012) Occult breast cancers manifesting as axillary lymph node metastasis in men: a two-case report. J Breast Cancer 15: 359-363.

9. He M, Liu H, Jiang Y (2015) A Case Report of Male Occult Breast Cancer First Manifesting as Axillary Lymph Node Metastasis With Part of Metastatic Mucinous Carcinoma. Medicine (Baltimore) 94 :e1038.

10. Harvey JA, Fajardo LL, Innis CA (1993) Previous mammograms in patients with impalpable breast carcinoma: Retrospective vs blinded interpretation. 1993 ARRS President's Award. Am J Roentgenol 161: 1167-1172.

11. Majid AS, de Paredes ES, Doherty RD, Sharma NR, Salvador X (2003) Missed breast carcinoma: pitfalls and pearls. Radiographics 23: 881-895.

12. Olson JA, Morris EA, Van Zee KJ, Linehan DC, Borgen PI (2000) Magnetic resonance imaging facilitates breast conservation for occult breast cancer. Ann Surg Oncol 7: 411-415.

13. de Bresser J, de Vos B, van der Ent F, Hulsewé K (2010) Breast MRI in clinically and mammographically occult breast cancer presenting with an axillary metastasis: a systematic review. Eur J Surg Oncol 36: 114-119. 
Citation: Pai VD, Manohar V, Kattimani K, Deshpande P, Tumbal S (2016) Occult Breast Carcinoma with Axillary Lymph Node Metastasis in a Male Patient - An Evidence Based Approach. J Nucl Med Radiat Ther 7: 293. doi:10.4172/2155-9619.1000293

Page 3 of 3

14. Fayanju OM, Jeffe DB, Margenthaler JA (2013) Occult primary breast cancer at a comprehensive cancer center. J Surg Res 185: 684-689.

15. Barton SR, Smith IE, Kirby AM, Ashley S, Walsh G (2011) The role of ipsilateral breast radiotherapy in management of occult primary breast cancer presenting as axillary lymphadenopathy. Eur J Cancer 47: 2099-2106.

16. Merson M, Andreola S, Galimberti V, Bufalino R, Walsh G (1992) Breast carcinoma presenting as axillary metastases without evidence of a primary tumor. Cancer 70: 504-508.

17. Baron PL, Moore MP, Kinne DW, Candela FC, Osborne MP, et al. (1990) Occult breast cancer presenting with axillary metastases. Updated management. Arch Surg 125: 210-214.
18. Wang X, Zhao Y, Cao X (2010) Clinical benefits of mastectomy on treatment of occult breast carcinoma presenting axillary metastases. Breast J 16: 32-37.

19. Macedo FIB, Eid JJ, Flynn J, Jacobs MJ, Mittal VK (2016) Optimal Surgical Management for Occult Breast Carcinoma: A Meta-analysis. Ann Surg Oncol 23: 1838-1844.

20. Masinghe SP, Faluyi OO, Kerr GR, Kunkler IH (2011) Breast radiotherapy for occult breast cancer with axillary nodal metastases--does it reduce the local recurrence rate and increase overall survival? Clin Oncol (R Coll Radiol) 23: 95-100. 